\title{
Impacting patient-centred outcomes in COPD: deconditioning
}

\section{R. Casaburi}

ABSTRACT: Patients with chronic obstructive pulmonary disease (COPD) frequently suffer from exercise intolerance, leading to a reduced ability to participate in activities of daily life and, therefore, to a reduced health-related quality of life (HRQoL). An important determinant of exercise intolerance is the loss of muscle mass.

Although the mechanism for loss of muscle function is multi-factorial, deconditioning appears to play a primary role in many patients. COPD patients often have decreased fat-free mass compared with healthy counterparts and reduced muscle cross-sectional area. It seems, then, that a cycle of decline often characterises COPD, in which inactivity results in muscle weakness, which in turn acts as a further deterrent to exercise. Such deconditioning can be reversed by pulmonary rehabilitation, leading to significant improvements in exercise tolerance and HRQoL.

Recent research suggests that the effectiveness of pulmonary rehabilitation can be amplified with concomitant administration of tiotropium (a long-acting bronchodilator) or supplemental oxygen. This suggests that facilitating higher training work-rates can enhance the anabolic effects of training.

Patients should be encouraged to maintain activity levels in the follow-up period after training, in order to retain the benefits of rehabilitation.

KEYWORDS: Chronic obstructive pulmonary disease, deconditioning, exercise tolerance, muscle dysfunction, pulmonary rehabilitation, tiotropium

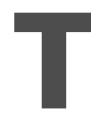
he defining feature of chronic obstructive pulmonary disease (COPD) is expiratory airflow limitation [1]. Patients with COPD also frequently suffer from exercise intolerance, leading to a reduced ability to participate in activities of daily living and to reduced healthrelated quality of life (HRQoL) [1]. Often, the reduction in the ability to exercise, participation in normal daily activities and HRQoL is out of proportion with the degree of lung function impairment [2-4]. For many years, it was widely assumed that because airflow limitation leads to dyspnoea, exercise intolerance was solely a function of the reduced ability to expel air. Because airflow limitation in COPD was formerly regarded as irreversible, little attention was paid to the prospect of improving exercise performance in COPD.

This rather negative view has fundamentally changed in recent years, with the development of more effective bronchodilators, as well as increased knowledge of the factors involved in exercise intolerance. The consensus view is that airway obstruction in COPD has a useful reversible component in most patients [5]. The development of long-acting bronchodilators has shown that improvements in airflow limitation in COPD can be maintained in the long term. Thus, long-acting anticholinergic agents and long-acting $\beta_{2}$-agonists are recommended for first-line maintenance treatment for COPD [1].

Moreover, it has been shown that ventilatory limitation is not the only factor limiting exercise tolerance, and is not always the most important. Muscle fatigue is now thought to be a significant contributor to exercise intolerance in COPD [4, 6]; this explains why studies have found that COPD patients are often limited by leg discomfort in addition to dyspnoea [7]. As their lung function declines, patients with COPD experience dyspnoea, which can be sufficiently distressing to prevent them from taking further physical exercise. As their level of physical activity falls, their muscles of ambulation undergo deconditioning, which involves structural and biochemical changes in the muscle cells. This results in even more discomfort upon exercising and further reduces the patient's capacity for physical activity.

Although physiological research has improved knowledge in recent years, important questions
CORRESPONDENCE

R. Casaburi

Rehabilitation Clinical Trials Center Division of Respiratory and Critical Care Physiology and Medicine

Los Angeles Biomedical Research Institute at Harbor-UCLA Medical Center

1124 West Carson Street

Torrance

California CA90502

USA

Fax: 13102228249

E-mail: casaburi@ucla.edu

CONFLICT OF INTEREST STATEMENT R. Casaburi has received honoraria from Boehringer Ingelheim (Ridgefield, CT, USA) and Pfizer (New York, NY, USA) for his participation at symposia. He has also acted as a consultant to Boehringer Ingelheim, Pfizer, AstraZeneca (Wilmington, DE, USA), Novartis (East Hanover, NJ, USA) and Inogen (Goleta, CA, USA), and is the recipient of a research grant from Altana (Konstanz, Germany). 
still remain. What are the contributors to skeletal muscle dysfunction in COPD, and to what extent is this dysfunction a result of deconditioning? To what extent can muscle fitness be normalised by training, and what impact does improving lung function have on the response to training and the maintenance of its effects? These questions, which are important for the optimal management of patients with COPD, will be addressed in the present article.

\section{MECHANISMS OF SKELETAL MUSCLE DYSFUNCTION IN COPD}

Skeletal muscle weakness has been observed in patients with COPD [8], and it is recognised as an important factor because it reduces exercise capacity. Numerous mechanisms contribute to poor muscle function in COPD. For example, patients with stable COPD have been shown to have significantly reduced thigh muscle cross-sectional area (CSA) compared with normal healthy subjects (fig. 1) [9]. The mean \pm SD CSA for COPD patients was $83.4 \pm 16.4 \mathrm{~cm}^{2}$ compared with $109 \pm$ $15.6 \mathrm{~cm}^{2}$ for normal subjects in that study $(\mathrm{p}<0.0001)$. COPD patients also had reduced strength in their quadriceps, pectoralis major and latissimus dorsi muscles compared with normal subjects [9]. The quadriceps' strength and thigh muscle CSA correlated significantly with the degree of airflow obstruction, but the muscle area/quadriceps' strength ratio was preserved in patients with COPD, which suggests that the loss of strength was predominantly the result of muscle atrophy [9]. The use of systemic corticosteroids was associated with a significant decrease in the strength of the quadriceps, although effects on the strength of the shoulder girdle muscles, the pectoralis major and latissimus dorsi muscles were not detected [9].

Other studies have found similar changes in the skeletal muscles of COPD patients. In patients with emphysema or chronic bronchitis, whole-body and extremity fat-free mass (FFM) were found to be significantly lower than in control patients $(p<0.05))[10]$. However, muscle function per kilogram of extremity FFM was not significantly different among the three groups. In a similar manner to the research of BERNARD et al. [9], this study suggested that the loss of skeletal muscle strength was a result of reduced muscle mass rather than loss of contractile properties. However, the study by BERNARD et al. [9] did not find a correlation between muscle function expressed per kilogram extremity FFM and forced expiratory volume in one second [10]. ENGELEN et al. [10] suggested that deconditioning due to chronic inactivity may be an important factor in contributing to the loss of extremity FFM in COPD patients.

An important insight was offered by SAEY et al. [6]. Half of a group of 18 COPD patients was found to have evidence of contractile fatigue of the quadriceps after a bout of constant work-rate cycle ergometer exercise. This subgroup did not increase their exercise tolerance when their lung function was improved by bronchodilator administration. This suggests that, for a substantial number of COPD patients, fatigue of the leg muscles, rather than ventilatory limitation, is the primary restriction to exercise tolerance. This finding enhances the attractiveness of pulmonary rehabilitation as a therapy for exercise intolerance in COPD [11].
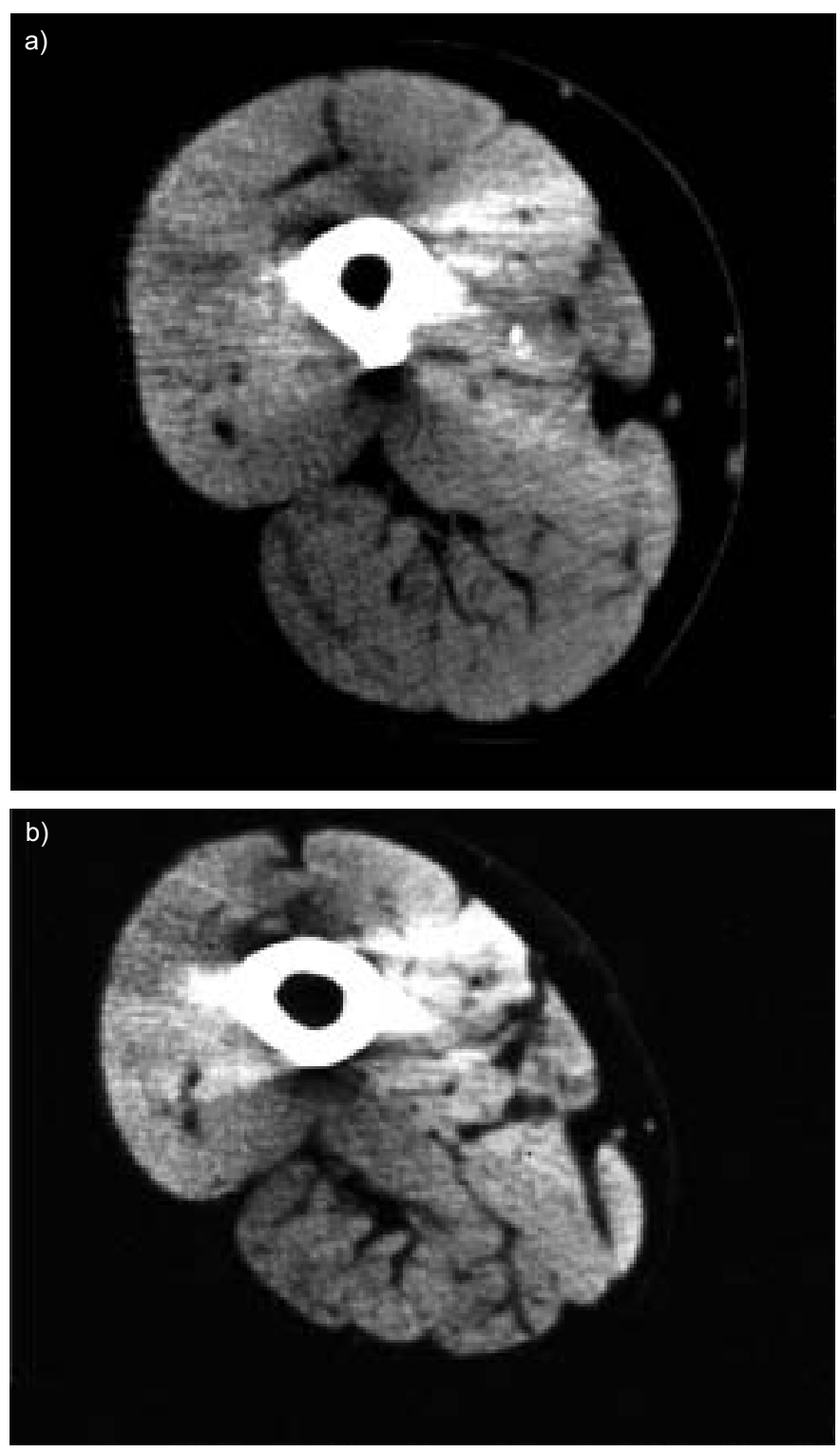

FIGURE 1. Computed tomography of the thigh muscle of a) a normal healthy subject and b) a patient with chronic obstructive pulmonary disease (COPD). The thigh muscle cross-sectional area was considerably reduced in the patient with COPD $\left(79.6 \mathrm{~cm}^{2}\right)$ compared with the normal healthy subject $\left(118.5 \mathrm{~cm}^{2}\right)$. Reprinted from [9] with permission from the publisher.

Based on these results, physical training in patients with COPD is likely to translate into restored muscle function and improved exercise tolerance. One study of normal-weight, FFM-depleted patients with moderate-to-severe COPD demonstrated that intensive, whole-body exercise training induced an anabolic response, increased weight by increasing FFM, and improved exercise performance and muscle function [12]. The improvements in exercise performance and muscle function were proportionally larger than the increases observed in FFM [12].

Although inactivity-induced atrophy is an important driver in the development of muscle abnormalities seen in patients with COPD, it is unlikely to be the only factor involved. Chronic 
hypoxaemia elicits a reduced force production [13]. There is evidence that muscle weakness is associated with systemic inflammation [14], oxidative stress [15], impaired oxidative capacity [16, 17], reduced capillarity [18] and reduced proportions of type I fibres [18, 19]. Testosterone, an androgenic steroidal hormone, can increase muscle size in healthy individuals [20], and a randomised, placebo-controlled, 10week trial in males with COPD found that testosterone increased lean body mass and strength [21]. Concomitant resistance training amplified the strength improvements. The study also demonstrated that a substantial majority of males with COPD had serum testosterone levels below the lower limit of the normal range for healthy young males (fig. 2) [21], which may conceivably explain, in part, their muscle weakness.

\section{PULMONARY REHABILITATION}

The main goals of pulmonary rehabilitation are to reduce the symptoms of COPD, improve the level of activity and daily function, and, thereby, restore a higher level of independence [22]. Pulmonary rehabilitation has been proven to be effective in a large number of well-designed, randomised, controlled clinical trials, and it is a key component of the management of COPD [23]. National guidelines and the World Health Organization's Global Initiative for Chronic Obstructive Lung Disease (GOLD) recommend the use of pulmonary rehabilitation in patients with COPD [1, 24, 25]. An analysis of pooled data from a number of trials demonstrated that pulmonary rehabilitation improves endurance time during a constant work-rate task by an average of $87 \%$, peak work-rate by an average of $18 \%$ and peak oxygen uptake by $11 \%$ compared with pre-rehabilitation levels [22]. In addition to improving exercise tolerance by relieving dyspnoea and fatigue in COPD patients, evidence has been presented that pulmonary rehabilitative exercise training also improves HRQoL [26], reduces the number of days spent in hospital and/or the number of hospitalisations [27] and is a cost-effective intervention [28].

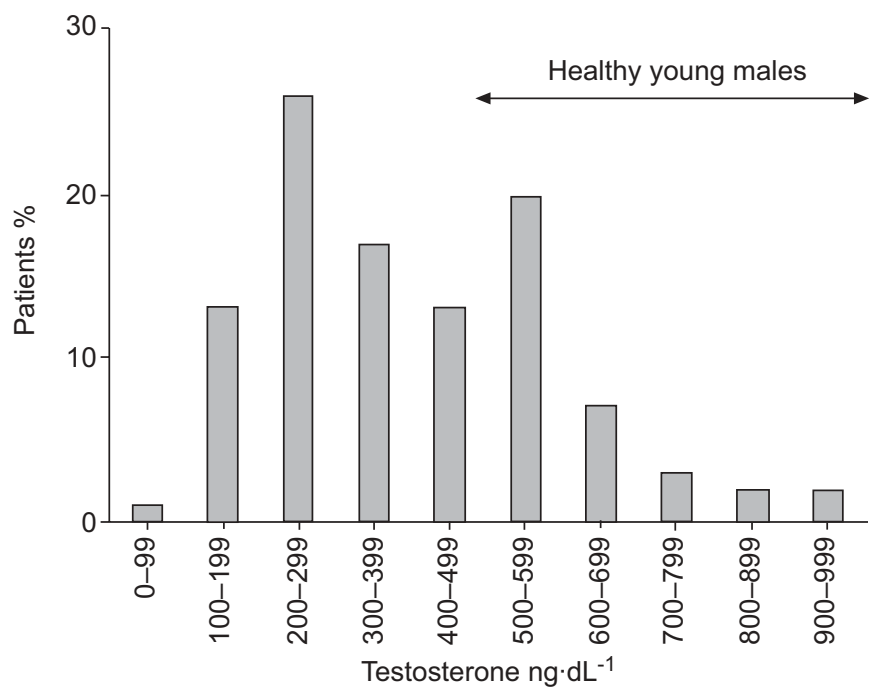

FIGURE 2. The serum testosterone levels of 81 males with chronic obstructive pulmonary disease who were screened for a randomised, placebo-controlled trial of testosterone and resistance training. Data taken and modified from [21].
In order to be optimally effective, pulmonary rehabilitation needs to allow patients to tolerate a level of exercise intensity that is high enough to provoke a physiological training effect. Strategies have been developed to help COPD patients perform more intense exercise training during pulmonary rehabilitation.

\section{MAXIMISING EXERCISE INTENSITY DURING REHABILITATION}

Pulmonary rehabilitation is a key component of the management of COPD, and the focus is now on finding ways to help patients achieve a higher volume of training. Strategies have been developed to allow them to 1) achieve higher levels of ventilation or 2) reduce their ventilatory requirement at a given level of exercise. A number of interventions have been considered, including breathing oxygen during training, use of bronchodilators, breathing of helium, pressure support ventilation and interval training.

Although previous findings for oxygen supplementation have generally been negative [22], a randomised, double-blind study of 30 patients with COPD demonstrated that oxygen supplementation at $3 \mathrm{~L} \cdot \mathrm{min}^{-1}$ was associated with a more rapid increase in the training work-rate over 21 sessions compared with air treatment (fig. 3) [29]. The mean \pm SD work-rate in the last week of training was also significantly higher in the oxygen-supplemented group compared with those patients breathing air $(62 \pm 19 \mathrm{~W}$ versus $52 \pm 22 \mathrm{~W}$, respectively; $\mathrm{p}<0.01)$ [29]. In laboratory testing, the group that trained with oxygen supplementation increased constant work-rate endurance time significantly more than those receiving compressed air treatment (14.5 versus 10.5 min, respectively; $p<0.05$ ) [29]. Another study found that long-term oxygen therapy provided benefits in terms of increased endurance times and reduced dyspnoea in COPD patients with reversible hypercapnia [30].

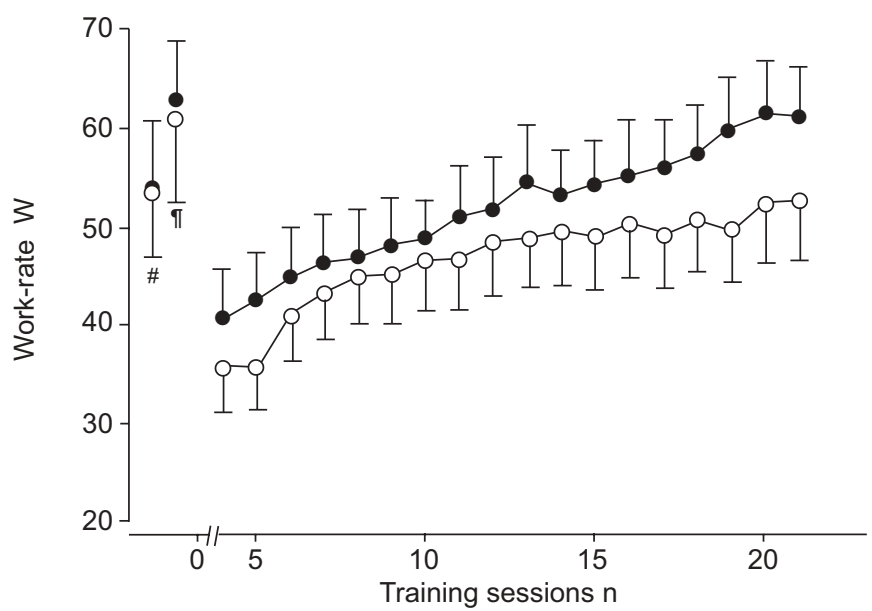

FIGURE 3. The progression of training work-rate over 21 sessions of pulmonary rehabilitation exercise in 29 patients with chronic obstructive pulmonary disease who breathed either oxygen $(\bullet)$ or compressed air $(\bigcirc)$ while training. ${ }^{*}$ : peak work-rate in the pre-training incremental exercise test breathing air (the same peak work-rate for both groups); ${ }^{\top}$ : peak work-rate while breathing $30 \%$ oxygen. Values and error bars represent the mean \pm SEM. Reprinted from [29] with permission from the publisher. 
Bronchodilators play a key role in the maintenance treatment of COPD [1] but there have been inconsistent results for the effects of bronchodilators on dyspnoea and exercise tolerance [31]. Newly developed agents for COPD, which offer sustained improvements in airflow, may be more effective in improving exercise tolerance in COPD. For example, tiotropium, a oncedaily, long-acting anticholinergic agent, was shown to increase post-dose exercise endurance by $105 \pm 40 \mathrm{~s}(21 \%)$ in patients with COPD compared with placebo [32]. The use of tiotropium was also associated with a decrease in dyspnoea on exertion, as measured using the Borg scale, and reduced lung hyperinflation at rest and during exercise $[32,33]$. In the only study of its kind, inhaled tiotropium (18 $\mu \mathrm{g}$ once daily) in combination with exercise training resulted in a significantly greater improvement $(32 \%)$ in constant work-rate endurance time following 8 weeks of rehabilitation compared with inhaled placebo (fig. 4) [34]. The difference between tiotropium and placebo was maintained for $\leqslant 12$ weeks after rehabilitation training, with a mean endurance time difference of $6.6 \mathrm{~min}$ at week $24(42 \% ; p=0.018)$ [34]. This study also found that tiotropium in combination with pulmonary rehabilitation improved dyspnoea and health status (as measured by the St George's respiratory questionnaire (SGRQ)) and the results were also sustained for $\leqslant 12$ weeks after rehabilitation training [34].

It is essential that once patients with COPD have undergone pulmonary rehabilitation, they maintain an adequate level of activity to ensure that their muscle condition remains improved. TROOSTERS et al. [22] recommend that patients with COPD should be offered once-weekly, high-intensity maintenance exercise training sessions following their initial pulmonary rehabilitation programme [22].

\section{ASSESSING PATIENT-CENTRED BENEFITS OF REHABILITATION}

The success of achieving the goals of pulmonary rehabilitation can be assessed using physiological and psychological

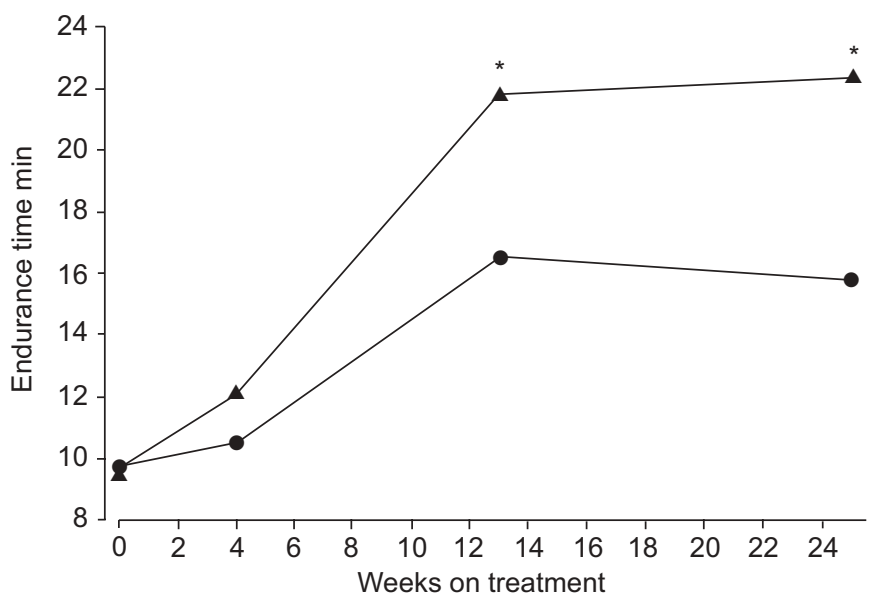

FIGURE 4. The effect of inhaled tiotropium (18 $\mu \mathrm{g}$ once daily) on the improvement in treadmill exercise endurance time in patients with chronic obstructive pulmonary disease undergoing pulmonary rehabilitation exercise sessions. Ninety-one patients received tiotropium or placebo for 4 weeks before, 8 weeks during and 12 weeks after a thrice-weekly rehabilitative exercise training programme. $\mathbf{\Delta}$ : patients treated with tiotropium; $\mathbf{0}$ : patients treated with placebo. *: $p<0.05$. Reprinted from [34] with permission from the publisher. measures, such as laboratory exercise tests, field exercise tests (e.g. the 6-min walk test or the shuttle walking test) and questionnaires to assess HRQoL (e.g. the SGRQ or the Chronic Respiratory Disease Questionnaire). When patients with COPD were asked to record their level of physical activity subjectively, they were found to over-report the extent of their activity compared with the objective recordings from video and an electronic activity monitor [35]. Therefore, when assessing the level of activity that patients with COPD maintain following pulmonary rehabilitation, it is essential to measure what the patient actually does, rather than what they are capable of doing or what they say that they are capable of doing. Ambulatory monitors may prove to be useful in this regard.

\section{CONCLUSIONS}

The growing understanding of the mechanisms of exercise limitation in chronic obstructive pulmonary disease patients has important implications for management. Pulmonary rehabilitation is now established as an important component of treatment, but maximising the effectiveness of such training depends upon effective concomitant treatment. Ideally, patients should be encouraged to maintain activity levels in the follow-up period following participation in a pulmonary rehabilitation programme.

\section{REFERENCES}

1 Global Initiative for Chronic Obstructive Lung Disease. Global strategy for the diagnosis, management, and prevention of chronic obstructive pulmonary disease, 2005. www.goldcopd.com. Date last accessed: September 25, 2006

2 Mahler DA, Harver A. A factor analysis of dyspnoea ratings, respiratory muscle strength, and lung function in patients with chronic obstructive pulmonary disease. Am Rev Respir Dis 1992; 145: 467-470.

3 Hamilton AL, Killian KJ, Summers E, Jones NL. Symptom intensity and subjective limitation to exercise in patients with cardiorespiratory disorders. Chest 1996; 110: 1255-1263.

4 Gosselink R, Troosters T, Decramer M. Peripheral muscle weakness contributes to exercise limitation in COPD. Am J Respir Crit Care Med 1996; 153: 976-980.

5 Celli BR, MacNee W, ATS/ERS Task Force. Standards for the diagnosis and treatment of patients with COPD: a summary of the ATS/ERS position paper. Eur Respir J 2004; 23: 932-946.

6 Saey D, Debigare R, LeBlanc P, et al. Contractile leg fatigue after cycle exercise: a factor limiting exercise in patients with chronic obstructive pulmonary disease. Am J Respir Crit Care Med 2003; 168: 425-430.

7 Killian KJ, LeBlanc P, Martin DH, et al. Exercise capacity and ventilatory, circulatory, and symptom limitation in patients with chronic airflow limitation. Am Rev Respir Dis 1992; 146: 935-940.

8 Hamilton AL, Killian KJ, Summers E, Jones NL. Muscle strength, symptom intensity, and exercise capacity in patients with cardiorespiratory disorders. Am J Respir Crit Care Med 1995; 152: 2021-2031. 
9 Bernard S, LeBlanc P, Whittom F, et al. Peripheral muscle weakness in patients with chronic obstructive pulmonary disease. Am J Respir Crit Care Med 1998; 158: 629-634.

10 Engelen MP, Schols AM, Does JD, Wouters EF. Skeletal muscle weakness is associated with wasting of extremity fat-free mass but not with airflow obstruction in patients with chronic obstructive pulmonary disease. Am J Clin Nutr 2000; 71: 733-738.

11 Casaburi R. Limitation to exercise tolerance in chronic obstructive pulmonary disease: look to the muscles of ambulation. Am J Respir Crit Care Med 2003; 168: 409-410.

12 Franssen FM, Broekhuizen R, Janssen PP, Wouters EF, Schols AM. Effects of whole-body exercise training on body composition and functional capacity in normalweight patients with COPD. Chest 2004; 125: 2021-2028.

13 Faucher M, Steinberg JG, Barbier D, Hug F, Jammes Y. Influence of chronic hypoxemia on peripheral muscle function and oxidative stress in humans. Clin Physiol Funct Imaging 2004; 24: 75-84.

14 Spruit MA, Gosselink R, Troosters T, et al. Muscle force during an acute exacerbation in hospitalised patients with COPD and its relationship with CXCL8 and IGF-I. Thorax 2003; 58: 752-756.

15 Couillard A, Koechlin C, Cristol JP, Varray A, Prefaut C. Evidence of local exercise-induced systemic oxidative stress in chronic obstructive pulmonary disease patients. Eur Respir J 2002; 20: 1123-1129.

16 Maltais F, Simard A-A, Simard C, et al. Oxidative capacity of the skeletal muscle and lactic acid kinetics during exercise in normal subjects and in patients with COPD. Am J Respir Crit Care Med 1996; 153: 288-293.

17 Maltais F, LeBlanc P, Whittom F, et al. Oxidative enzyme activities of the vastus lateralis muscle and the functional status in patients with COPD. Thorax 2000; 55: 848-853.

18 Jobin J, Maltais F, Doyon JF, et al. Chronic obstructive pulmonary disease: capillarity and fiber-type characteristics of skeletal muscle. J Cardiopulm Rehabil 1998; 18: 432-437.

19 Whittom F, Jobin J, Simard PM, et al. Histochemical and morphological characteristics of the vastus lateralis muscle in patients with chronic obstructive pulmonary disease. Med Sci Sports Exerc 1998; 30: 1467-1474.

20 Sinha-Hikim I, Artaza J, Woodhouse L, et al. Testosteroneinduced increase in muscle size in healthy young men is associated with muscle fiber hypertrophy. Am J Physiol Endocrinol Metab 2002; 283: E154-E164.

21 Casaburi R, Bhasin S, Cosentino L, et al. Effects of testosterone and resistance training in men with chronic obstructive pulmonary disease. Am J Respir Crit Care Med 2004; 170: 870-878.
22 Troosters T, Casaburi R, Gosselink R, Decramer M. Pulmonary rehabilitation in chronic obstructive pulmonary disease. Am J Respir Crit Care Med 2005; 172: 19-38.

23 Lacasse Y, Brosseau L, Milne S, et al. Pulmonary rehabilitation for chronic obstructive pulmonary disease. Cochrane Database Syst Rev 2002; 3: CD003793.

24 American Thoracic Society. Pulmonary rehabilitation 1999. Am J Respir Crit Care Med 1999; 159: 1666-1682.

25 National Institute for Clinical Excellence. Chronic obstructive pulmonary disease. Thorax 2004; 59: 1-232.

26 Foglio K, Bianchi L, Ambrosino N. Is it really useful to repeat outpatient pulmonary rehabilitation programs in patients with chronic airway obstruction? A 2-year controlled study. Chest 2001; 119: 1696-1704.

27 Hui KP, Hewitt AB. A simple pulmonary rehabilitation program improves health outcomes and reduces hospital utilization in patients with COPD. Chest 2003; 124: 94-97.

28 Griffiths TL, Phillips CJ, Davies S, Burr ML, Campbell IA. Cost effectiveness of an outpatient multidisciplinary pulmonary rehabilitation programme. Thorax 2001; 56: 779-784.

29 Emtner M, Porszasz J, Burns M, Somfay A, Casaburi R. Benefits of supplemental oxygen in exercise training in nonhypoxemic chronic obstructive pulmonary disease patients. Am J Respir Crit Care Med 2003; 168: 1034-1042.

30 Haidl P, Clement C, Wiese C, Dellweg D, Kohler D. Longterm oxygen therapy stops the natural decline of endurance in COPD patients with reversible hypercapnia. Respiration 2004; 71: 342-347.

31 Rennard SI, Anderson W, ZuWallack R, et al. Use of a longacting inhaled $\beta_{2}$-adrenergic agonist, salmeterol xinafoate, in patients with chronic obstructive pulmonary disease. Am J Respir Crit Care Med 2001; 163: 1087-1092.

32 O'Donnell DE, Flüge T, Gerken F, et al. Effects of tiotropium on lung hyperinflation, dyspnoea and exercise tolerance in patients with COPD. Eur Respir J 2004; 23: 832-840.

33 Maltais F, Hamilton A, Marciniuk D, et al. Improvements in symptom-limited exercise performance over $8 \mathrm{~h}$ with once-daily tiotropium in patients with COPD. Chest 2005; 128: 1168-1178.

34 Casaburi R, Kukafka D, Cooper CB, Witek TJ Jr, Kesten S. Improvement in exercise tolerance with the combination of tiotropium and pulmonary rehabilitation in patients with COPD. Chest 2005; 127: 809-817.

35 Pitta F, Troosters T, Spruit MA, Decramer M, Gosselink R. Activity monitoring for assessment of physical activities in daily life in patients with chronic obstructive pulmonary disease. Arch Phys Med Rehabil 2005; 86: 1979-1985. 